\title{
Endoscopic Management of Iatrogenic Colon Perforation
}

\author{
Yunho Jung \\ Division of Gastroenterology, Department of Medicine, Soonchunhyang University College of Medicine, Cheonan, Korea
}

Colon perforations are difficult to resolve because they occur unexpectedly and infrequently. If the clinician is unprepared or lacks training in dealing with perforations, the clinical prognosis will be affected, which can lead to legal issues. We describe here the proper approach to the management of perforations, including deciding on endoscopic or surgical treatment, selection of endoscopic devices, endoscopic closure procedures, and general management of perforations that occur during diagnostic or therapeutic colonoscopy. Clin Endosc 2020;53:29-36

Key Words: Colon; Perforation

\section{INTRODUCTION}

The risk of complications associated with diagnostic and therapeutic colonoscopies is increasing because of the focus on the prevention, early diagnosis, and treatment of colorectal cancer, as well as the expansion of the indications for endoscopic resection of precancerous and malignant lesions. A colon perforation is defined as a full-thickness tissue defect involving all four layers (mucosa, submucosa, muscularis propria, and serosa) of the colon wall and resulting in pneumoperitoneum. The size of the perforation is estimated on the basis of the length of the hemoclip when the hemoclip jaws are fully opened. ${ }^{1}$ Perforation is one of the most common complications that can occur unexpectedly during diagnostic and therapeutic colonoscopies. Colon perforation is rare but important because there is a high possibility of peritonitis caused by fecal materials, which can be life-threatening or

Received: March 3, 2019 Revised: April 17, 2019

Accepted: April 18, 2019

Correspondence: Yunho Jung

Division of Gastroenterology, Department of Medicine, Soonchunhyang University College of Medicine, 31 Suncheonhyang 6-gil, Dongnam-gu, Cheonan 31151, Korea

Tel: +82-41-570-3741, Fax: +82-041-574-5762, E-mail: yoonho7575@naver.com ORCID: https://orcid.org/0000-0002-7760-0050

(c) This is an Open Access article distributed under the terms of the Creative Commons Attribution Non-Commercial License (http://creativecommons.org/ licenses/by-nc/3.0) which permits unrestricted non-commercial use, distribution, and reproduction in any medium, provided the original work is properly cited. associated with mortality if appropriate treatment is delayed. ${ }^{2}$ According to a meta-analysis of studies on perforation from 2001 to 2015, the pooled prevalence rates of perforation and mortality were 0.5 in 1,000 (95\% confidence interval [CI], 0.40.7 ) and 2.9 in 100,000 (95\% CI, 1.1-5.5) colonoscopies. Colonoscopy with polypectomy was associated with a perforation rate of 0.8 in 1,000 (95\% CI, 0.6-1.0). ${ }^{3}$ The rates of immediate and delayed perforation were $4.2 \%$ (95\% CI, 3.5\%-5.0\%) and $0.22 \%$ (95\% CI, $0.11 \%-0.46 \%$ ), respectively, in a meta-analysis of 13,833 cases of colorectal endoscopic submucosal dissection (ESD) from 1998 to $2014{ }^{4}$

The mechanisms of perforation associated with colonoscopy are as follows: (1) direct mechanical trauma caused by the forward movement of the tip of the colonoscope, (2) lateral pressure against the bowel wall caused by bowing of a loop of the scope, (3) passage of the endoscope through areas of pathology (e.g., strictures, tumors, and diverticula), (4) barotrauma caused by excessive air insufflation, and (5) application of electrosurgical current during therapeutic procedures (e.g., polypectomy and ESD). ${ }^{1,2,5}$ Resolution of perforations requires a multidisciplinary approach, in which surgical treatment is the basic principle. However, under appropriate circumstances and indications, endoscopic closure of perforations is possible and may result in better outcomes than those of surgical treatment. Thus, we review the factors that should be considered before deciding on endoscopic treatment, as well as the endoscopic closure techniques and prediction of post-procedure 
prognosis after iatrogenic colon perforation.

\section{CHARACTERISTICS AND RISK FACTORS OF COLON PERFORATIONS}

The sigmoid colon is the most common site of perforation and is the location of $51 \%-53 \%$ of perforations that occur during a diagnostic colonoscopy. ${ }^{5,6}$ This is not only because the sigmoid colon is the most tortuous and challenging section, but also because it is a common location of pedunculated polyps, diverticula, and postoperative adhesions. Rectal perforation often occurs when retroflexion is performed, and the cecum is the most common site of perforation from barotrauma, typically in the setting of difficult colonoscopy and overinflation. ${ }^{2}$ Owing to its thinner mural wall, the right colon is at an increased risk of perforation during therapeutic procedures such as polypectomy.

The reported risk factors for diagnostic colonoscopy-associated perforations are the presence of multiple comorbidities, bowel obstruction, advanced age, female sex, and diverticulosis. ${ }^{7}$ During a therapeutic colonoscopy, a lateral spreading or nonpolypoid morphology, polyp location in the cecum or right colon, a nonlifting polyp after submucosal injection owing to submucosal fibrosis or deep layer involvement, polyps $>1 \mathrm{~cm}$ in size, and multiple polyps are risk factors for perforation. $^{7-12}$ Sometimes, the dissected muscularis propria appears as a white to gray central circular disc in the cross section of the specimen, and the target is surrounded by a web of bluestained submersible connective tissue (after the injection), which is called a "target sign" because it resembles a target. The identification of a target sign after endoscopic mucosal resection on the underside of the specimen and a mirror target at the resection site is potentially indicative of full-thickness resection (perforation) and should be promptly treated with endoscopic closure (Fig. 1). ${ }^{13}$

Diagnostic colonoscopy-associated perforations are rela- tively large and have a greater likelihood of requiring surgery than therapeutic colonoscopy-associated perforations. The mean size of the perforation $(19.3 \pm 12.8 \mathrm{~mm}$ vs. $5.8 \pm 2.9 \mathrm{~mm}$, $p=0.01$ ) and the frequencies of the peritoneal irritation sign (61.5\% vs. $24.0 \%, p=0.035)$ and emergency surgery $(53.8 \%$ vs. $8.0 \%, p=0.003$ ) are significantly higher for diagnostic colonoscopy-associated perforations than for therapeutic colonoscopy-associated perforations. Irrespective of whether hemoclipping is performed, the probability of improvement after conservative treatment $(92.0 \%$ vs. $46.2 \%, p=0.003)$ is significantly higher for therapeutic colonoscopy-associated perforations than for diagnostic colonoscopy-associated perforations. $^{14}$

\section{SYMPTOMS AND DIAGNOSIS}

The symptoms of colon perforation (e.g., no pain, localized instantaneous pain, and severe cramp-like pain with distension of the abdomen) differ according to the cause, size, and site of the perforation. ${ }^{15,16}$ Most (94\%) patients with colon perforation develop abdominal pain, and the most frequent sign is tachycardia (54\%), followed by guarding and rebound tenderness, abdominal distention, leukocytosis, fever, and hypotension. However, $6 \%$ of colon perforations are asymptomatic. ${ }^{5}$ The time to the diagnosis of colon perforation is $\leq 24$ $\mathrm{h}$ in about $75 \%$ of patients and $\leq 96 \mathrm{~h}$ in about $98 \%{ }^{7}$ However, caution is needed because colon perforation is diagnosed after $\geq 2$ weeks in some cases. ${ }^{17}$

Colon perforation can be diagnosed in various ways, such as the identification of a mucosal defect during a colonoscopy and detection (on plain radiography) of pneumoperitoneum caused by free air in the peritoneal cavity, retroperitoneal space, mesentery, or ligaments of organs. ${ }^{15}$ Computed tomography (CT) of the abdomen and pelvis is the most useful diagnostic tool for colon perforations, and has great accuracy in detecting small amounts of free air and fluid in the peritoneal
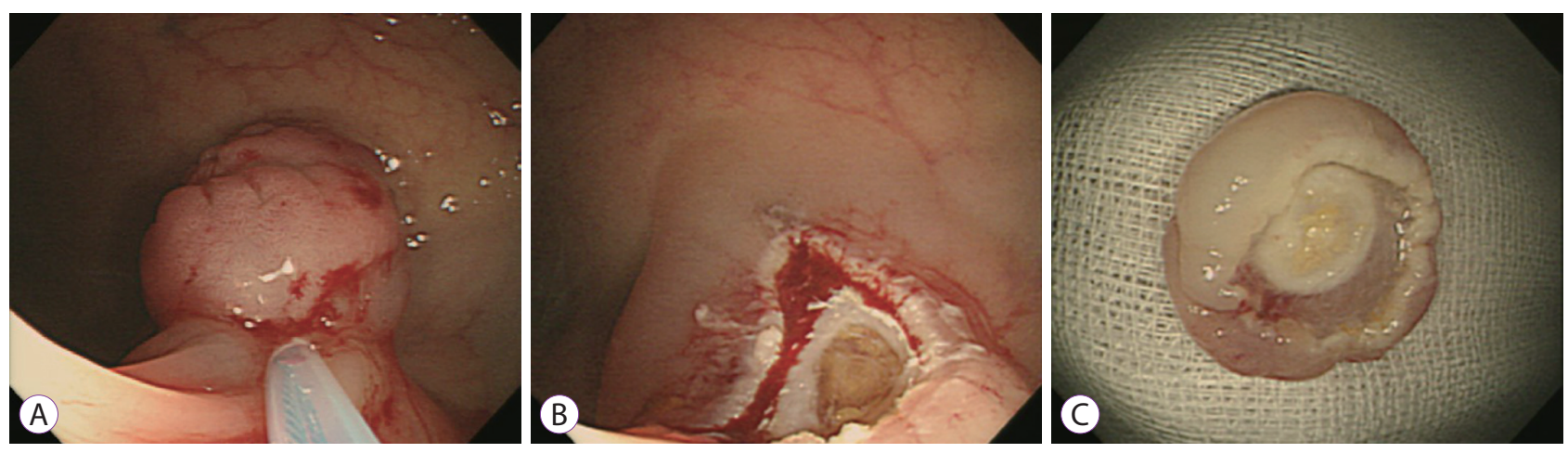

Fig. 1. (A) A 7-mm sessile polyp was resected using a snare. (B) A perforation was observed at the site of polypectomy. (C) Mirror target sign of the specimen. 
cavity. In addition, one of the important advantages of CT is that it has a high probability of finding the perforation site. ${ }^{18}$

\section{BASIC PRINCIPLES OF PERFORATION MANAGEMENT}

\section{Approach is dependent on expertise}

A novice endoscopist should stop air insufflation when an iatrogenic perforation occurs during an endoscopic procedure, and the supervisor or an expert endoscopist should be contacted as soon as possible. Intraluminal fluid should be suctioned out as much as possible and the position of the patient should be changed so that the perforation site is opposite to gravity, to prevent the leakage of fluid or fecal content. The supervisor or expert endoscopist should decide carefully and promptly whether to observe, perform endoscopic closure, or perform surgery. ${ }^{19}$

\section{Surgical versus endoscopic management}

The decision of endoscopic closure should be made taking into account the quality of bowel preparation; time to diagnosis; comorbidities; clinical stability and symptoms; and endoscopic factors such as the available devices, endoscopist expertise, and type and size of the perforation. ${ }^{1,1920}$ The European Society of Gastrointestinal Endoscopy guidelines recommend considering endoscopic closure if the bowel is clean within $4 \mathrm{~h}$ of colon perforation. ${ }^{20}$ Fujishiro et al. ${ }^{21}$ stated that there are four criteria for closing an acute iatrogenic perforation with metallic clips: (1) the perforation must be $<1 \mathrm{~cm}$; (2) the gastrointestinal (GI) tract must be as clean as possible; (3) the procedure must be conducted by an expert endoscopist; and (4) there should be no deterioration of clinical symptoms or laboratory indices, which should be monitored by an experienced surgeon.

Unlike therapeutic colonoscopy-associated perforations, diagnostic colonoscopy-associated perforations are often caused by excessive manipulation of the colonoscope by an inexpe- rienced endoscopist. Because such perforations are usually large, caution is required when deciding whether to perform surgery.

\section{General management}

Immediately after the recognition of an iatrogenic perforation, a check for tension pneumoperitoneum should be performed and, if present, it should be immediately decompressed with wide-bore needle puncture. ${ }^{22}$ Concomitant administration of intravenous fluids, broad-spectrum antibiotics, and close clinical monitoring by a multidisciplinary team of intensive care physicians, endoscopists, and surgeons are needed.

\section{ENDOSCOPIC MANAGEMENT OF COLON PERFORATION}

If a perforation is to be closed using an endoscopic method, carbon dioxide endoscopic insufflation should be initiated where possible. The endoscopic closure devices should be selected according to the location, type, and size of the iatrogenic perforation (Table 1).

\section{Through-the-scope clips}

Endoscopic closure of an iatrogenic perforation with metallic clips after snare excision was first described by Binmoeller et al. ${ }^{23}$ in 1993. Through-the-scope clips (TTSCs) are used for endoscopic mechanical hemostasis and, since the late 1990s, for endoscopic closure of perforations. Several types of TTSC are available, including Resolution Clip (Boston Scientific Inc., Natick, MA, USA), Instinct Clip (Cook Medical Inc., Bloomington, IN, USA), and Quick Clip (Olympus America Inc., Center Valley, PA, USA).

Endoclips create mucosal and submucosal apposition, whereas apposition of the muscularis propria and serosa is not possible because of the superficial bite of the clips. In animal models, superficial apposition of the colonic wall is sufficient

Table 1. Endoscopic Closure Methods according to Perforation Size

\begin{tabular}{lccc}
\hline Size of perforation & \multicolumn{3}{c}{ Endoscopic closure methods consideration } \\
\hline & First & Second & Third \\
$\leq 1 \mathrm{~cm}$ & Hemoclips & OTSC & Band ligation \\
& (cheap, easy to get, immediate use) & (difficult location) \\
$1-2 \mathrm{~cm}$ & Hemoclips or OTSC & Endoloop-clip \\
$2-3 \mathrm{~cm}$ & Endoloop-clip & OTSC & \\
$\geq 3 \mathrm{~cm}$ & & Consider surgery & \\
\hline
\end{tabular}

OTSC, over-the-scope clip. 
to obtain adequate healing of the perforation. ${ }^{24}$ Moreover, clinical studies have demonstrated the appropriateness of perforation closure with TTSCs. ${ }^{1,25,26}$ In a recent meta-analysis, the success rate of endoscopic closure of colon perforations was $83.8 \%$ (212 of 253). However, most cases of perforations occurred during therapeutic colonoscopy and most of the perforations were small. ${ }^{25}$

The following are technical tips for the use of TTSCs for iatrogenic perforations: ${ }^{19,22}$ (1) Position the wide-open clip across the defect at a $90^{\circ}$ angle. (2) Fix the clip arms on the tissue surrounding the defect. (3) Slowly apply the endoclips with proper approximation to prevent slippage on the grasped tissue. (4) Place additional clips sequentially from one direction to the other, particularly for large perforations (top to bottom for linear perforations and left to right for circular perforations are recommended after satisfactory application of the first clip).(5) Apply hemoclips until the perforation is sealed. (6) Suction and decompress the lumen before withdrawing the endoscope (Fig. 2).

If the first clip is incorrectly applied and interferes with the application of the next clip, removal of the first clip should be considered. However, it should be noted that the perforation can sometimes increase in size because of tearing of tissue during removal. Transparent caps have the advantages of reducing the amount of insufflated gas, anchoring the endoscope during the application of clips, and facilitating the approach to a difficult position, which can be useful in the management of perforations.

If perforation occurs during a therapeutic procedure, such as ESD, immediate closure of the perforation with endoscopic clips can interfere with the complete removal of the lesion.
Unless the perforation is large enough to require surgery, a position change and suction are recommended to prevent the leakage of fluid or fecal content. If an additional submucosal dissection is required for making space for submucosal dissection or snaring after hemoclipping, it should be performed as soon as possible. The lesion can be removed using hybrid $\mathrm{ESD}^{27}$ or endoscopic piecemeal resection before or after applying the hemoclips (Fig. 3).

\section{Over-the-scope clips}

The over-the-scope clip (OTSC) system (Ovesco Endoscopy AG, Tübingen, Germany) is composed of a super-elastic and shape-memory alloy (nitinol) and is designed to achieve full-thickness closure with teeth arranged in the shape of a bear trap. The nitinol clip is mounted on a clear distal cap at the end of the endoscope and is deployed by turning a wheel. In animal models, reliable full-thickness closure of defects of about $30 \mathrm{~mm}$ was achieved using this device. ${ }^{28,29}$ The OTSC produces more durable closure than standard endoclips ${ }^{30}$ because of its ability to grasp more tissue, include the entire thickness of the visceral wall, and apply a greater compressive force.

According to a meta-analysis of the clinical results of OTSC from 2010 to 2018, the success rate of GI perforation was 85\% $(n=351) .{ }^{31}$ OTSC closure of colonic perforations was successful in $100 \%$ of the cases ( $n=14$; colon, 8 cases; rectum, 4 cases) ${ }^{32}$ and in $92 \%$ (12 of 13 cases) $)^{33}$ of colonic perforations associated with polypectomy.

Very small perforations can be closed using an OTSC after suction without the aid of accessory devices to enable perforation sealing. Bidirectional grasping forceps (twin grasper;
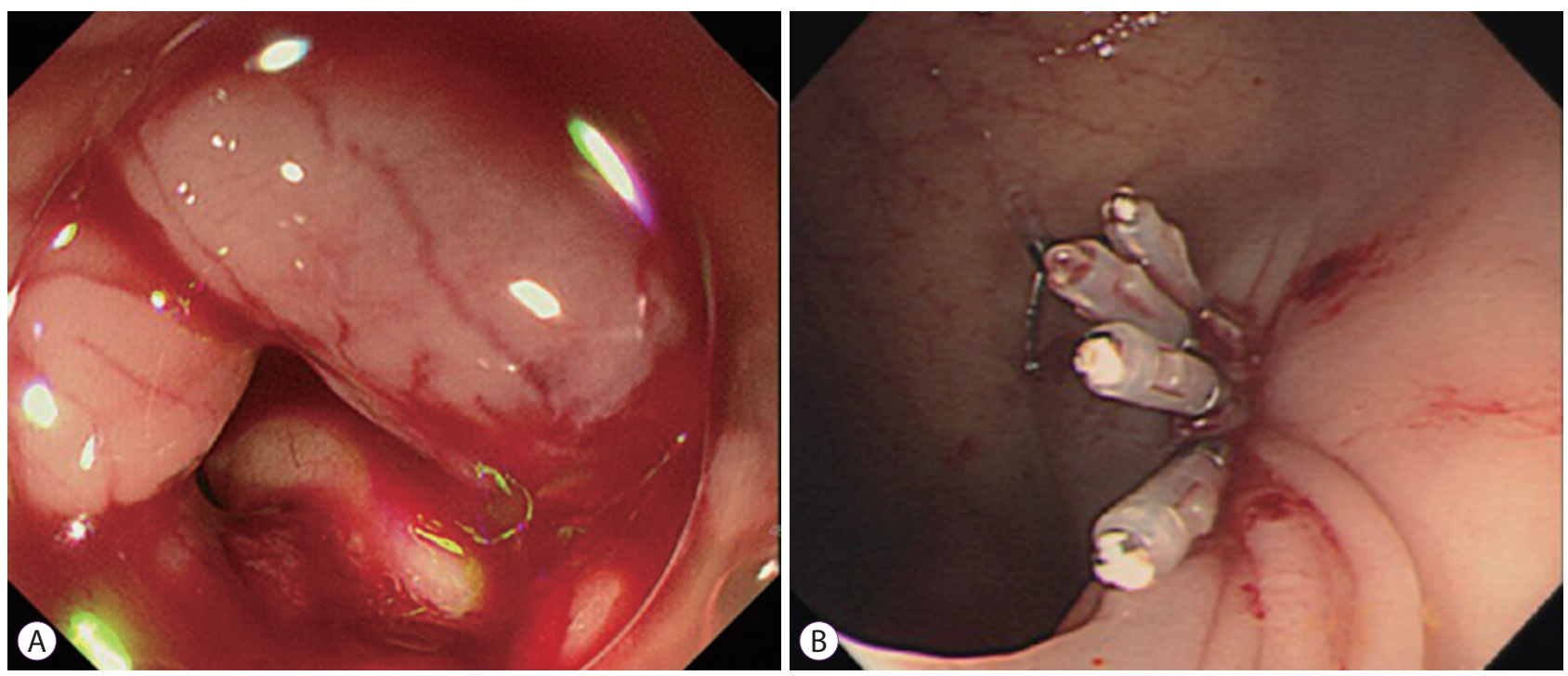

Fig. 2. (A) A 6-mm penetrating perforation occurred in the sigmoid colon during a diagnostic colonoscopy. (B) Successful closure of the perforation with hemoclips. 
Ovesco Endoscopy, Tübingen, Germany) are useful for approximation of both edges of a defect. The closure process with OTSCs is as follows $\mathrm{s}^{29}$ : (1) Grasp one of the lateral edges of the perforation using one arm of the twin grasper. (2) Grasp the opposing edge of the perforation with the second arm of the OTSC twin grasper to bring the two sides of the perforation into contact. (3) Pull the re-apposed tissue into the OTSC cap and maintain enough suction to aspirate the tissue surrounding the perforation into the cap. (4) Release the OTSC by turning a wheel on the shaft of the endoscope like in the endoscopic band-ligation technique (Fig. 4).

\section{Band-ligation technique}

A small perforation at a position where it is difficult to use an endoscopic clip can be closed using the band-ligation method. There have been few reports on the use of band ligation for colon perforations; however, the technique was useful in a clinical case, ${ }^{34}$ as well as in pig $^{35}$ (100\% of six cases) and $\operatorname{dog}^{36}(100 \%$ of seven cases) models.

When using the band-ligation technique, it is important to maintain adequate distance between the perforation site and the endoscopic banding cap so that the surrounding tissues, including the perforation site, are sufficiently sucked into the banding cap before deploying the band; a "pink or red out sign" indicates sufficiency in this regard (Fig. 5). However, because of the limited size of the endoscopic cap, it is indicated only for small perforations. ${ }^{19}$

\section{Endoloop-clips technique}

The combined use of TTSCs and an endoloop is one of the methods that can be attempted if an OTSC device is unavailable when a $\geq 20$-mm colon perforation, which is difficult to close with hemoclips, occurs. ${ }^{37} \mathrm{~A} \geq 3$-cm oval rectal perforation $^{38}$ and six cases of 2 -cm colon perforations ${ }^{39}$ were reported to be successfully closed using this combination technique.

The endoloop-clips technique is performed as follows: (1) Place an endoloop through one channel around the perforated tissue using a double-channel endoscope. (2) Apply several hemoclips through the other channel to fix the endoloop and surrounding perforated tissues. (3) Tighten the endoloop to close or reduce the perforation. (4) Completely close any remaining defect using additional hemoclips with or without an endoloop (Fig. 6).

\section{Self-expendable metal stents}

Self-expandable metal stents (SEMSs) are indicated for perforations such as Boerhaave's syndrome and iatrogenic perforation and GI tract leaks (e.g., fistula) after bariatric surgery, as
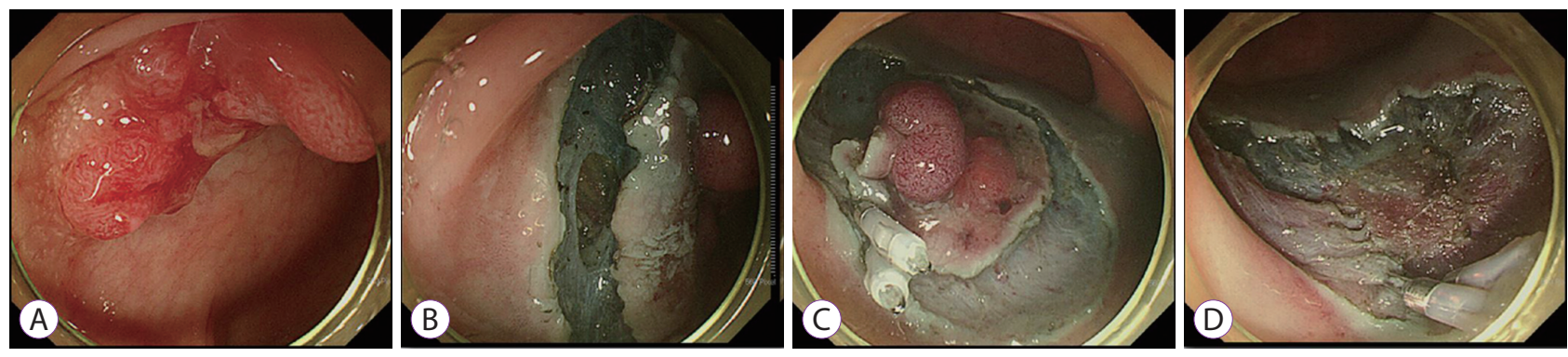

Fig. 3. (A) A 2-cm nodular mixed-type lateral spreading tumor in the rectosigmoid colon. (B) A 4-mm perforation occurred during an endoscopic submucosal dissection (ESD). (C) After further dissection of the submucosal layer, hemoclips were applied to the perforation and the circumferential incision was completed. (D) The lesion was removed using the hybrid ESD technique.
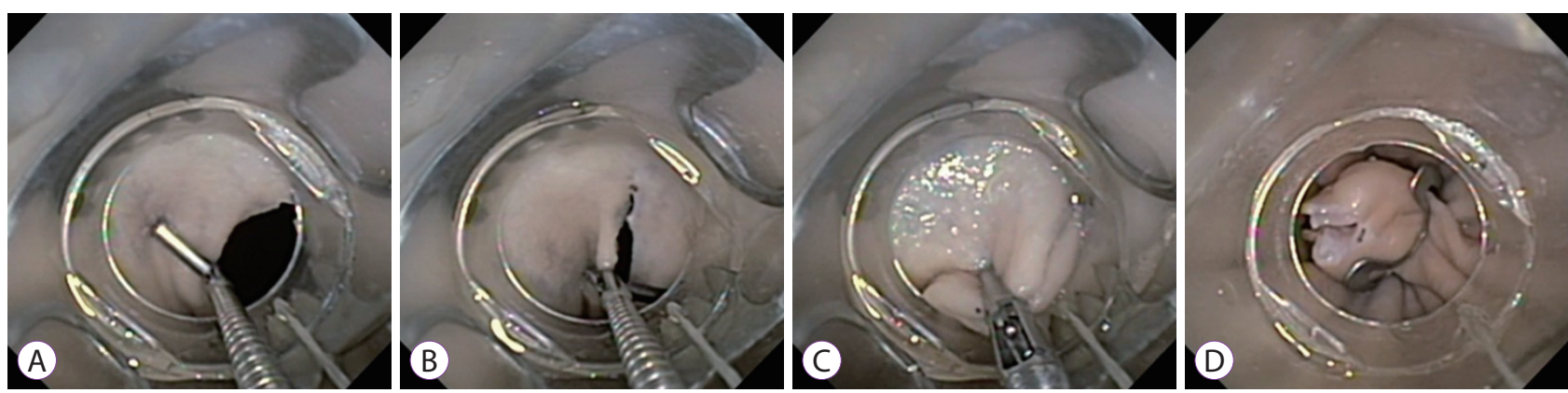

Fig. 4. (A) One of the lateral edges of the defect was grasped using one arm of the twin grasper. (B) The other edge of the defect was grasped using the second arm of the twin grasper. (C) The re-apposed tissue was pulled into the over-the-scope clip (OTSC) cap. (D) The OTSC was released by turning a wheel on the shaft of the endoscope. 

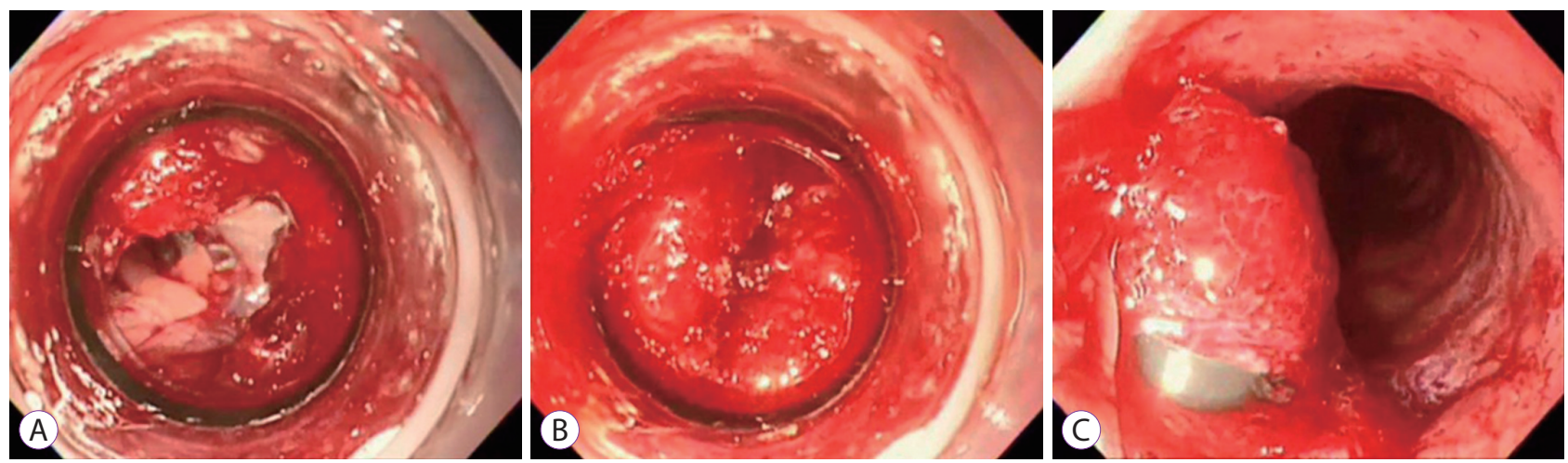

Fig. 5. (A) An approximately 7-mm perforation in the intestine. (B) The surrounding perforated tissues and the perforation were suctioned sufficiently into the banding cap until a "pink or red out sign" was observed. (C) The iatrogenic perforation was successfully closed using the band-ligation method (Adapted from Jung ${ }^{19}$ ).
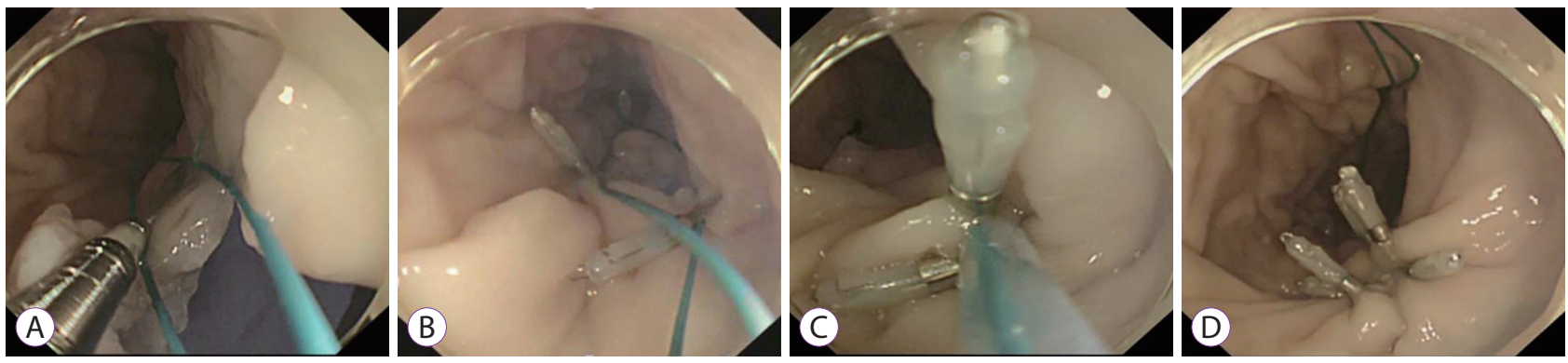

Fig. 6. (A) The endoloop was placed around the perforated tissue through one channel of a double-channel endoscope. (B) Several hemoclips were applied through the other channel to fix the endoloop and surrounding perforated tissues. (C) The endoloop was tightened to close or reduce the perforation. (D) Complete closure of the perforation was achieved (Adapted from Jung ${ }^{19}$ ).

well as for other postoperative fistulae. ${ }^{22,40}$ SEMSs are mostly employed in the upper GI tract and are particularly useful for large esophageal perforations. ${ }^{20}$ There are few reports on the use of SEMSs for colon perforations. A fully covered SEMS was successfully used to close an iatrogenic perforation during dilatation of a colonic anastomotic stricture. ${ }^{41}$ Use of a fully covered SEMS may be considered for colon perforations with a stricture.

\section{POST-ENDOSCOPY MANAGEMENT}

Broad-spectrum intravenous antibiotics and bowel rest are important after endoluminal closure of a perforation. The patient should be closely monitored in collaboration with the surgeon for signs of peritoneal irritation, to prevent clinical deterioration. ${ }^{20,22}$

The risk factors associated with the need for surgery within $24 \mathrm{~h}$ of endoscopic clip closure are a large perforation (odds ratio [OR], 9.25; 95\% CI, 1.85-46.20), severe abdominal pain (OR, 4.30; 95\% CI, 1.17-15.83), fever (OR, 5.05; 95\% CI, 1.0524.28), leukocytosis (OR, 6.58; 95\% CI, 1.86-23.29), and a large amount of peritoneal free air (OR, 4.05; 95\% CI, 1.40-11.71).
In addition, endoscopic clipping followed by diffuse peritoneal symptoms is a major risk factor for surgery. ${ }^{43}$ Early recognition of a perforation and immediate closure to decrease the likelihood of bacterial contamination are associated with a satisfactory outcome. If the clinical condition deteriorates because of contamination, early surgical consultation should be suggested. Oral food intake can be resumed after the resolution of pain and fever, return of appetite and bowel function, and normalization of laboratory signs of inflammation (e.g., leukocytosis and an elevated C-reactive protein level). ${ }^{22}$

Endoscopic clip closure of colon perforations has several limitations. First, evaluation of the closure of the perforation after endoscopic clip closure is difficult. Second, delayed complications (e.g., peritoneal abscess) can develop because of extraluminal contaminants or intermittent minor leakage. Third, procedure-related adverse events can occur. A prolonged procedure time and an increase in the air supply can aggravate abdominal distention and increase the risk of peritoneal infection. Fourth, laparoscopic closure after endoscopic clipping can interfere with the attachment of multiple clips at the perforation site. ${ }^{42}$

The instrument used for OTSC or band ligation should be equipped with a clip or band on the cap, and the en- 
doloop-clips technique should be performed using a double-channel endoscope. For these reasons, the colonoscope should be withdrawn and re-inserted, which limits the approach to perforations of the right colon. However, these methods are feasible because most large perforations during diagnostic colonoscopy occur in the sigmoid colon.

\section{CONCLUSIONS}

Endoscopic closure of iatrogenic colon perforations can prevent hospitalization and unnecessary surgery. However, the decision to perform endoscopic closure, as well as the method used, should take into consideration the patient's condition, bowel preparation quality, time to diagnosis, available devices, endoscopist expertise, and type and size of the perforation.

\section{Conflicts of Interest}

The author has no financial conflicts of interest.

\section{REFERENCES}

1. Jovanovic I, Zimmermann L, Fry LC, Mönkemüller K. Feasibility of endoscopic closure of an iatrogenic colon perforation occurring during colonoscopy. Gastrointest Endosc 2011;73:550-555.

2. Cotton PB, Eisen GM, Aabakken L, et al. A lexicon for endoscopic adverse events: report of an ASGE workshop. Gastrointest Endosc 2010;71:446-454.

3. Reumkens A, Rondagh EJ, Bakker CM, Winkens B, Masclee AA, Sanduleanu S. Post-colonoscopy complications: a systematic review, time trends, and meta-analysis of population-based studies. Am J Gastroenterol 2016;111:1092-1101.

4. Akintoye E, Kumar N, Aihara H, Nas H, Thompson CC. Colorectal endoscopic submucosal dissection: a systematic review and meta-analysis. Endosc Int Open 2016;4:E1030-E1044.

5. Avgerinos DV, Llaguna OH, Lo AY, Leitman IM. Evolving management of colonoscopic perforations. J Gastrointest Surg 2008;12:1783-1789.

6. Iqbal CW, Cullinane DC, Schiller HJ, Sawyer MD, Zietlow SP, Farley DR. Surgical management and outcomes of 165 colonoscopic perforations from a single institution. Arch Surg 2008;143:701-706; discussion 706-707.

7. Panteris V, Haringsma J, Kuipers EJ. Colonoscopy perforation rate, mechanisms and outcome: from diagnostic to therapeutic colonoscopy. Endoscopy 2009;41:941-951.

8. Wada Y, Kudo SE, Tanaka S, et al. Predictive factors for complications in endoscopic resection of large colorectal lesions: a multicenter prospective study. Surg Endosc 2015;29:1216-1222.

9. Rutter MD, Nickerson C, Rees CJ, Patnick J, Blanks RG. Risk factors for adverse events related to polypectomy in the English Bowel Cancer Screening Programme. Endoscopy 2014;46:90-97.

10. Lee EJ, Lee JB, Choi YS, et al. Clinical risk factors for perforation during endoscopic submucosal dissection (ESD) for large-sized, nonpedunculated colorectal tumors. Surg Endosc 2012;26:1587-1594.

11. Kim ES, Cho KB, Park KS, et al. Factors predictive of perforation during endoscopic submucosal dissection for the treatment of colorectal tumors. Endoscopy 2011;43:573-578.

12. Thirumurthi S, Raju GS. Management of polypectomy complications.
Gastrointest Endosc Clin N Am 2015;25:335-357.

13. Swan MP, Bourke MJ, Moss A, Williams SJ, Hopper A, Metz A. The target sign: an endoscopic marker for the resection of the muscularis propria and potential perforation during colonic endoscopic mucosal resection. Gastrointest Endosc 2011;73:79-85.

14. Yang DH, Byeon JS, Lee KH, et al. Is endoscopic closure with clips effective for both diagnostic and therapeutic colonoscopy-associated bowel perforation? Surg Endosc 2010;24:1177-1185.

15. Iqbal CW, Chun YS, Farley DR. Colonoscopic perforations: a retrospective review. J Gastrointest Surg 2005;9:1229-1235: discussion 1236.

16. Cobb WS, Heniford BT, Sigmon LB, et al. Colonoscopic perforations: incidence, management, and outcomes. Am Surg 2004;70:750-757; discussion 757-758.

17. Anderson ML, Pasha TM, Leighton JA. Endoscopic perforation of the colon: lessons from a 10-year study. Am J Gastroenterol 2000;95:34183422.

18. Paspatis GA, Vardas E, Theodoropoulou A, et al. Complications of colonoscopy in a large public county hospital in Greece. A 10-year study. Dig Liver Dis 2008;40:951-957.

19. Jung Y. Management of gastrointestinal tract perforations. Gastrointestinal Intervention 2017;6:157-161.

20. Paspatis GA, Dumonceau JM, Barthet M, et al. Diagnosis and management of iatrogenic endoscopic perforations: European Society of Gastrointestinal Endoscopy (ESGE) position statement. Endoscopy 2014;46:693-711.

21. Fujishiro M, Yahagi N, Kakushima N, et al. Successful nonsurgical management of perforation complicating endoscopic submucosal dissection of gastrointestinal epithelial neoplasms. Endoscopy 2006;38:1001-1006.

22. Raju GS. Endoscopic closure of gastrointestinal leaks. Am J Gastroenterol 2009;104:1315-1320.

23. Binmoeller KF, Grimm H, Soehendra N. Endoscopic closure of a perforation using metallic clips after snare excision of a gastric leiomyoma. Gastrointest Endosc 1993;39:172-174.

24. Raju GS, Ahmed I, Xiao SY, et al. Controlled trial of immediate endoluminal closure of colon perforations in a porcine model by use of a novel clip device (with videos). Gastrointest Endosc 2006;64:989-997.

25. Verlaan T, Voermans RP, van Berge Henegouwen MI, Bemelman WA, Fockens P. Endoscopic closure of acute perforations of the GI tract: a systematic review of the literature. Gastrointest Endosc 2015;82:618-628. e5.

26. Hawkins AT, Sharp KW, Ford MM, Muldoon RL, Hopkins MB, Geiger TM. Management of colonoscopic perforations: a systematic review. Am J Surg 2018;215:712-718.

27. Jung Y, Kim JW, Byeon JS, et al. Factors predictive of complete excision of large colorectal neoplasia using hybrid endoscopic submucosal dissection: a KASID multicenter study. Dig Dis Sci 2018;63:2773-2779.

28. von Renteln D, Schmidt A, Vassiliou MC, Rudolph HU, Caca K. Endoscopic full-thickness resection and defect closure in the colon. Gastrointest Endosc 2010;71:1267-1273.

29. Matthes K, Jung Y, Kato M, Gromski MA, Chuttani R. Efficacy of full-thickness GI perforation closure with a novel over-the-scope clip application device: an animal study. Gastrointest Endosc 2011;74:13691375.

30. von Renteln D, Vassiliou MC, Rothstein RI. Randomized controlled trial comparing endoscopic clips and over-the-scope clips for closure of natural orifice transluminal endoscopic surgery gastrotomies. Endoscopy 2009;41:1056-1061.

31. Kobara H, Mori H, Nishiyama N, et al. Over-the-scope clip system: a review of 1517 cases over 9 years. J Gastroenterol Hepatol 2019;34:22-30.

32. Haito-Chavez Y, Law JK, Kratt T, et al. International multicenter experience with an over-the-scope clipping device for endoscopic management of GI defects (with video). Gastrointest Endosc 2014;80:610-622.

33. Voermans RP, Le Moine O, von Renteln D, et al. Efficacy of endoscopic closure of acute perforations of the gastrointestinal tract. Clin Gastroenterol Hepatol 2012;10:603-608. 
34. Han JH, Park S, Youn S. Endoscopic closure of colon perforation with band ligation; salvage technique after endoclip failure. Clin Gastroenterol Hepatol 2011;9:e54-e55.

35. Yang Y, Lin X, Tan S, et al. Endoscopic band ligation is able to close perforations caused by colonoscopy: a porcine model study. Gastroenterol Res Pract 2018;2018:4325675.

36. Han JH, Kim M, Lee TH, et al. Endoluminal closure of colon perforation with endoscopic band ligation: technical feasibility and safety in an in vivo canine model. Clin Endosc 2015;48:534-541.

37. Martínek J, Ryska O, Tuckova I, et al. Comparing over-the-scope clip versus endoloop and clips (KING closure) for access site closure: a randomized experimental study. Surg Endosc 2013;27:1203-1210.

38. Katsinelos P, Lazaraki G, Chatzimavroudis G, Zavos C. Closure of an iatrogenic rectal perforation with the endoloop/clips technique in a purse-string fashion. Ann Gastroenterol 2014;27:264.

39. Ryu JY, Park BK, Kim WS, et al. Endoscopic closure of iatrogenic colon perforation using dual-channel endoscope with an endoloop and clips: methods and feasibility data (with videos). Surg Endosc 2019;33:13421348 .

40. Swinnen J, Eisendrath P, Rigaux J, et al. Self-expandable metal stents for the treatment of benign upper GI leaks and perforations. Gastrointest Endosc 2011;73:890-899.

41. Kim SW, Lee WH, Kim JS, Lee HN, Kim SJ, Lee SJ. Successful management of colonic perforation with a covered metal stent. Korean J Intern Med 2013;28:715-717.

42. Cho SB, Lee WS, Joo YE, et al. Therapeutic options for iatrogenic colon perforation: feasibility of endoscopic clip closure and predictors of the need for early surgery. Surg Endosc 2012;26:473-479.

43. Taku K, Sano Y, Fu KI, et al. Iatrogenic perforation associated with therapeutic colonoscopy: a multicenter study in Japan. J Gastroenterol Hepatol 2007;22:1409-1414. 